NBER WORKING PAPER SERIES

SUPPLY SHOCKS, WAGE INDEXATION

AND MONETARY ACCOMMODATION

Joshua Aizenman

Jacob A. Frenkel

Working Paper No. 1609

NATIONAL BUREAU OF ECONOMIC RESEARCH

1050 Massachusetts Avenue

Cambridge, MA 02138

April 1985

An earlier version of this paper was presented at the NBER-World Bank Conference on Structural Adjustment and the Real Exchange Rate in Developing Countries, Washington, D.C., November 29-December 1 , 1984. We wish to acknowledge helpful comments by Stanley Fischer. The research reported here is part of the NBER's research programs in International Studies and Economic Fluctuations. Any opinions expressed are those of the authors and not those of the National Bureau of Economic Research. 
NBER Working Paper \#1609

April 1985

Supply Shocks, Wage Indexation

and Monetary Accommodation

\title{
ABSTRACT
}

\begin{abstract}
This paper develops a unified framework for the analysis of wage indexation and monetary policy in the presence of supply shocks. We first present simple formulae for the optimal wage indexation rule and for the optimal money supply rule. In order to set the stage for an evaluation of departures from the optimal policy rules we first analyse two extreme cases -- a rule that stabilizes employment and a rule that stabilizes the real wage. The analysis of these two extreme cases provides the ingredients for the evaluation of various rules for wage indexation and for monetary targeting. We examine the implications of indexing wages to (i) nominal GNP, (ii) the CPI and (iii) the value-added price index, as well as the implications of targeting the money supply to these alternative three indicators. It is shown that, the various indexation mles bear a dual relation to the various monetary targeting rules. The welfare ranking of the various rules depends on whether the elasticity of the demand for labor exceeds or falls short of the elasticity of labor supply. If the demand for labor is more elastic than the supply, then policy rules that stabilize employment produce a smaller welfare cost than policy rules that stabilize the real wage. In that case, indexing wages to nominal GNP results in a smaller welfare cost than indexing to value-added price index which, in turn, produces a smaller cost than indexation to the CPI. Because of the dual relation between monetary policy and wage indexation, it follows that under the same circumstances, monetary policy that targets nominal GNP produces a smaller welfare cost than policy that targets the value-added price index which, in turn, results in a smaller cost than the policy that targets the CPI. This ranking is reversed when the elasticity of the supply of labor exceeds the elasticity of demand.
\end{abstract}

Professor Joshua Aizenman

Graduate School of Business

University of Chicago

1101 E. 58th Street

Chicago, IL 60637

(312) $962-7260$
Professor Jacob A. Frenkel

Department of Economics

University of Chicago

1126 E. 59th Street

Chicago, IL 60637

(312) 962-8253 
The energy crises of the 1970's stimulated a renewed interest in questions concerning the proper adjustment to external supply shocks. In general, restoration of equilibrium in response to shocks necessitates adjustment of both quantities and prices. When applied to labor markets, various proposals for policy rules attempting to restore labor-market equilibrium may be classified in terms of their impact on the division of adjustment between quantities (the level of employment) and prices (the real wage). The design of optimal policies provides for the appropriate division of this adjustment.

This paper develops a unified framework for the analysis of wage indexation and monetary policy. The analytical framework is applied to determine the optimal policy rules in the presence of supply shocks as well as to evaluate the welfare consequences and ranking of alternative (suboptimal) policy rules. In order to set the stage for an evaluation of the welfare implications of alternative policy rules, we first analyse two extreme cases -- a rule that stabilizes employment and a rule that stabilizes the real wage. The analysis of these two extreme cases provides the ingredients for the evaluation of various rules for wage-indexation and for monetary targeting. We examine the implications of indexing wages to (i) nominal GNP, (ii) the CPI and (iii) the value-added price index. The distinction between the CPI and the value-added price index is of a special importance in the presence of supply shocks. We also examine the implications of targeting the money supply to these alternative three indicators. Our analysis demonstrates that, on the formal level, the various indexation rules bear a dual relation to the various monetary targeting rules. We show that the welfare ranking of the various rules depends on whether the elasticity of the demand for labor exceeds or falls short of the elasticity of labor supply. Specifically, if the demand for labor is more 
elastic than the supply, then policy rules that stabilize employment produce a smaller welfare cost than policy rules that stabilize the real wage and vice-versa. Accordingly, using this principle, we show that if the elasticity of the demand for labor exceeds the elasticity of supply then, indexing wages to nominal GNP results in a smaller welfare cost than indexing to the value-added price index which, in turn, produces a smaller cost than indexation to the CPI. Likewise, because of the dual relation between monetary policy and wage indexation, it follows that under the same circumstances, monetary policy that targets nominal GNP produces a smaller welfare cost than policy that targets the value-added price index which, in turn, results in a smaller cost than the policy that targets the CPI. This ranking is reversed when the elasticity of the supply of labor exceeds the elasticity of demand.

Our analysis is of relevance to both the theory and the policy discussions concerning wage indexation and monetary rules. Specifically. great attention has been given to the question of whether the monetary authority, when faced with a higher price of imported energy, should follow an accommodative policy and expand the money supply in order to "finance" the higher energy price or, whether it should be anti-accommodative and contract the money supply in order to lower inflation. The key question was whether, In the absence of an active monetary response, labor markets can adjust without costly deviations from full employment [e.g. Gordon (1975, 1984), Phelps (1978), Blinder (1981), Rasche and Tatom (1981) and Fischer (1985)]. Our analysis deals with these questions as part of the more general analytical framework.

Section I describes the building blocks of the model including the specification of the stochastic shocks and the determination of output and employment. Section II introduces the objective function which aims at minimizing the expected value of labor-market distortions. In our model, as in Gray (1976) and Fischer (1977a, 1977c), the need for wage-indexation and 
monetary policy arises from the existence of labor-market contracts according to which wages are set in advance of the realization of the stochastic shocks. This labor-market convention results in some stickiness of wages. Wage indexation and monetary policies intend to reduce the undesirable consequences of this stickiness. With the aid of the objective function we derive the optimal wage indexation rule which eliminates the welfare cost. The key characteristic of the optimal indexation rule is that it separates between the effects of monetary and real shocks on the wage.

In Section III we examine the implications of departures from the optimal indexation rule. In this context we develop a general criterion for the comparisons between rules that stabilize employment and rules that stabilize real wages. We then apply this criterion to determine the welfare ranking of alternative proposals for wage indexation rules.

The question of monetary accommodation is addressed in section IV. We start by specifying the conditions for monetary equilibrium. We then determine the optimal money-supply rule and analyse its dependence on (i) the nature of the stochastic shocks (ii) the parameters of the demand for money, (iii) the elasticities of the demand for and supply of labor, and (iv) the degree of wage indexation. The section concludes with an analysis of various targeting rules for monetary policies. Analogously to the comparisons among wage-indexation rules, the monetary rules are analysed in terms of their relative impact on stabilizing quantities (employment) versus stabilizing prices (the real wage). Finally, section $V$ contains concluding remarks. 


\section{The Model}

In this section we outline the structure of the model which includes a specification of the productive technology, and a determination of the levels of output, employment and wages.

\section{I.1 Output and Employment}

Output is assumed to be produced by a Cobb-Douglas production function using labor and imported energy as variable inputs. Thus, for period $\mathrm{t}$,

$$
\log Y_{t}=\log B+B \log L_{t}+\lambda \log V_{t}+\mu_{t} \quad, 0 \leq \beta<1,0 \leq \lambda<1
$$

where $Y_{t}$ denotes the level of output, $L_{t}$ and $V_{t}$ denote, respectively, the inputs of labor and energy, $B$ denotes a parameter including all fixed factors of production and $\mu_{t}$ denotes a productivity shock. The productivity shock is assumed to be distributed independently and normally with a zero mean and a known variance $\sigma_{\mu}^{2}$. In competitive equilibrium the parameters $B$ and $\lambda$ denote, respectively, the relative shares of labor income and energy bill in national product. Throughout the analysis we assume that information is complete; thus, producers and other agents in the economy know the realized values of the stochastic shocks. 1

Producers, who are assumed to maximize profits, demand labor and energy so as to equate the real wage and the relative price of energy to the marginal products of labor and energy. Expressed logarithmically, these equalities are

(2) $\quad \log \left(\frac{W}{P}\right)_{t}=\log \beta B-(1-\beta) \log L_{t}+\lambda \log V_{t}+\mu_{t}$ 


$$
\log \left(\frac{P}{P}\right)_{t}=\log \lambda B+B \log L_{t}-(1-\lambda) \log v_{t}+\mu_{t}
$$

where $W, P_{v}$ and $P$ denote the nominal wage, the nominal price of energy and the price level, respectively.

Equations (1)-(3) characterize the levels of output and factor inputs for a given realization of the stochastic productivity shock $\mu_{t}$. In the absence of stochastics shocks, the corresponding levels of output and factor inputs are denoted by $Y_{0}, L_{0}$ and $V_{0}$ and the corresponding real factor prices are $(W / P)_{0}$ and $\left(P_{v} / P\right)_{0}$. For subsequent use we denote by lower case letters the percentage discrepancy of a variable from the value obtained in the absence of shocks. Thus, $x=108 x-108 x_{0}$. Accordingly, the percentage deviation of output from its non-stochastic level is

(1') $\quad y=B 2+\lambda v+\mu$

where $y=\log Y_{t}-\log Y_{0}, \ell=\log L_{t}-\log L_{0}$, and $v=\log V_{t}-\log V_{0}$. Analogously, subtracting from equations (2) and (3) the corresponding equations for the non-stochastic equilibrium yields

(2') $\quad w-p=-(1-b) l+\lambda v+\mu$

(3') $\quad p_{v}-p=B l-(1-\lambda) v+\mu$

where, for simplicity, the time subscript has been omitted. From equations (2') and (3') the demands for labor and energy (or more precisely the percentage discrepancy of the demands for labor and energy from their nonstochastic levels) are 
(4)

$$
\begin{aligned}
& \ell=\sigma\left[(1-\lambda)(p-w)-\lambda\left(p_{v}-p\right)+\mu\right] \\
& v=\sigma\left[o(p-w)-(1-\beta)\left(p_{v}-p\right)+\mu\right] \\
& \text { where } \sigma=\frac{1}{1-p-\lambda} .
\end{aligned}
$$

Assuming that producers are always able to satisfy their demands for labor and energy inputs, we substitute equations (4) and (5) into (1') and obtain

$$
y=\sigma\left[\beta(p-w)-\lambda\left(p_{V}-p\right)+\mu\right] \quad .
$$

Equation (6), which may be viewed as the aggregate supply function, shows that the percentage deviation of output from its deterministic level depends on the percentage deviations of the real wage and of the relative price of energy from their deterministic levels, as well as on the real productivity shock $\mu$. Higher values of the real wage and of the real energy price operate like negative supply shocks and result in lower output, whereas a positive productivity shock raises output.

We assume that the economy is small in the world energy market and that it faces an exogenously given energy price which is distributed normally around a given mean. In order to simplify the notations we define an effective real shock $u$ as the sum of the positive supply shocks arising from shocks to productivity and to the price of imported energy. Thus $u=\mu-\lambda\left(p_{v}-p\right)$. With this definition of the effective real shock, the demand for labor in equation (4) and the supply of output in equation (6) can be written as:

(4') $l=n(p-w)+\sigma u$ 
and

(6') $\quad y=\sigma[B(p-w)+u]$.

where $\eta=\sigma(1-\lambda)$ denotes the (absolute value of the) elasticity of the demand for labor with respect to the real wage. This specification of employment and output (or more precisely the percentage discrepancy of employment and output from their non-stochastic levels) reflects the assumption that $\ell$ and $y$ are determined exclusively by the demand for labor rather than by the interaction between the demand and the supply of labor. ${ }^{2}$ The resultant disequilibrium in the labor market induces welfare cost and our subsequent analysis deals with ways to minimize this welfare cost. In order to obtain a benchmark for the assessment of the implications of distortions in the labor market, we turn first to an analysis of the equilibrium that would have obtained in the absence of distortions.

\section{I.2 The Undistorted Equilibrium}

In the undistorted equilibrium the demand for labor equals the supply. Let the supply of labor be

$$
\log L_{t}^{S}=\log A+\varepsilon \log \left(\frac{W}{P}\right)_{t}
$$

where $\varepsilon$ denotes the elasticity of labor supply. As before, using lowercase letters to denote the percentage deviation of labor supply from the non-stochastic level, we obtain

(7') $\quad \ell^{S}=\varepsilon(w-p) \quad$. 
Equating the demand for labor (equation ( $\left.4^{\prime}\right)$ ) with the supply (equation $\left(7^{\circ}\right)$ yields the undistored equilibrium employment, $\vec{l}$, and the undistorted equilibrium real wages, $(w-p)$ :

$$
\tilde{\ell}=\frac{\varepsilon \sigma}{\varepsilon+n} u
$$

Using equation (9) in (6') yields the undistorted equilibrium output $\tilde{y}$ :

$$
(w-p)=\frac{\sigma}{\varepsilon+n} u
$$

(10) $\quad \tilde{y}=\frac{(1+\varepsilon) \sigma}{\varepsilon+n} u$.

When this equilibrium obtains, the demand for labor equals the supply of labor and, in the absence of other distortions, efficiency is maximized.

I1. The Measure of Welfare Loss and Optimal Indexation

Tne foregoing analysis determined the equilibrium undistorted levels of output, employment and real wages. It was assumed that the flexibility of wages and prices yielded an undistorted labor market equilibrium. The values of the key variables in the undistorted equilibrium serve as the benchmark against which the actual levels of output, employment and real wages can be compared. Such comparisons provide the basis for the computation of the welfare loss of labor market distortions. In this section we outline a measure of the welfare loss and we discuss the optimal policies designed to eliminate this loss. A more formal derivation of the measure of welfare loss is presented in the Appendix. 


\section{1 The Welfare Loss}

It is assumed that due to costs of negotiations nominal wages are set in advance at their expected market clearing level, and employment is determined by the demand for labor. For a given realization of the effective real shock, $u$, the resulting level of employment is $\ell$, as given by equation (4'). The corresponding equilibrium level of employment is $\bar{l}$, as given by equation (4'"), obtained by substituting into (4') the equilibrium real wage $(w-p)$ for the actual real wage.

(4') $\quad \bar{l}=n(p-w)+o u \quad$.

The discrepancy between $\tilde{\ell}$ and $\ell$ is responsible for the welfare loss. That discrepaney is

$$
\tilde{\ell}-\ell=n l-(w-p)+(w-p)] .
$$

In order to compute the welfare loss associated with this discrepancy we need to multiply it by one half of the difference between the demand and the supply prices at the actual level of employment. Diagramatically, in Figure $1 \quad \vec{l}$ and $\left(w_{-}^{-}\right)$designate the equilibrium values of employment and real wages, whereas $\ell$ designates actual employment. At the actual employment level, $\ell$, the demand price for labor, $(w-p)$, exceeds the corresponding supply price, $(w-p)^{S}$. The welfare loss is represented by $\Delta$ measuring the area of the triangle $A B C$. This triangle expresses the welfare loss in terms of consumer and produces surpluses. Thus,

$$
\Delta=\frac{1}{2}\left[(w-p)^{d}-(w-p)^{s}\right](\tilde{l}-l) .
$$




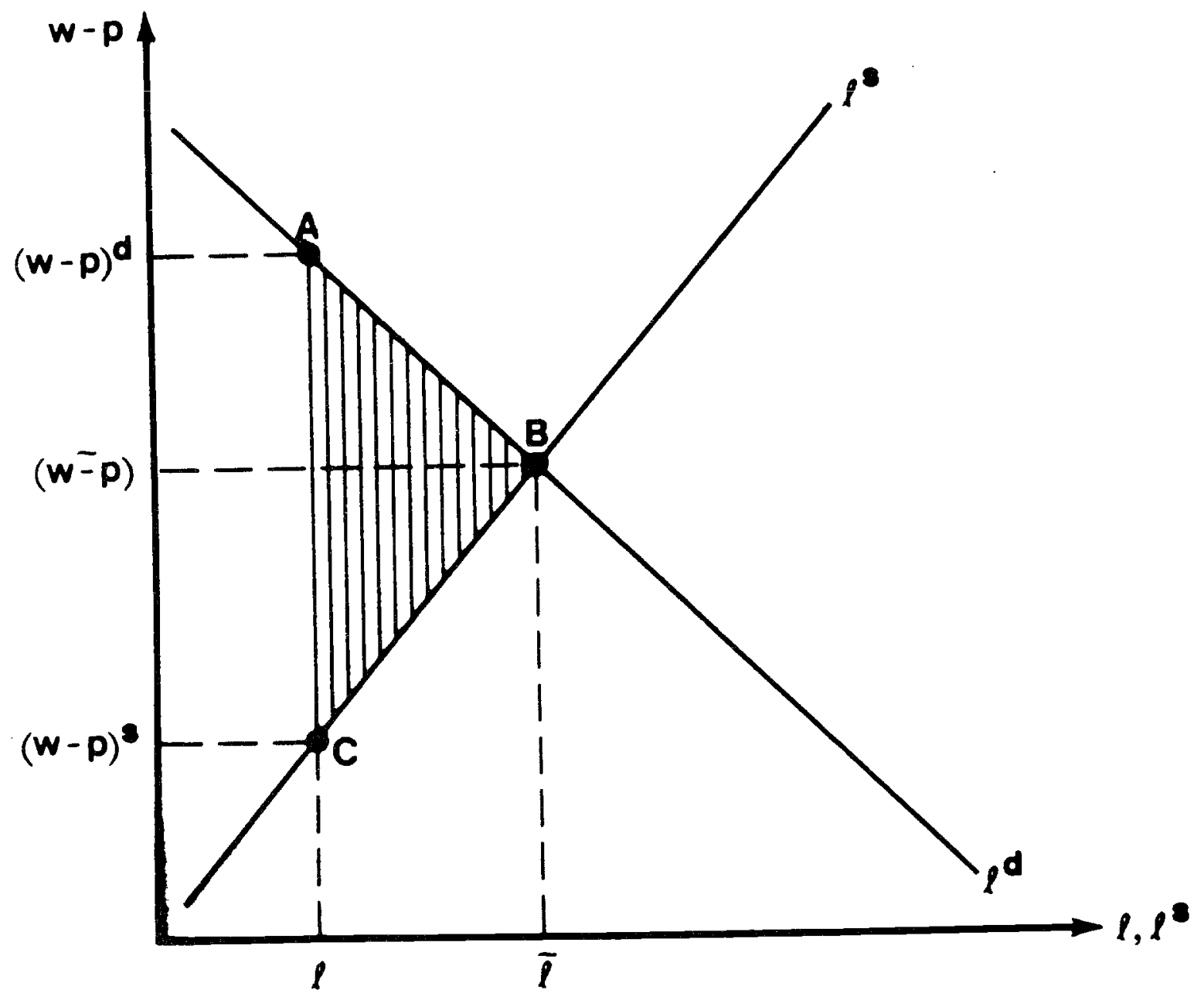

Fiqure - 1 
By using the definitions of the elasticities of the demand and the supply of labor we note that $(w-p)^{d}-(w-p)^{s}=\left(\frac{1}{\varepsilon}+\frac{1}{n}\right)(\tilde{l}-\ell)$. Substituting into (12) and recalling that the equilibrium real wage, $(w-p)$, is specified by equation ( 9$)$, yields

$$
\Delta=\frac{1}{2} n \frac{\varepsilon+\eta}{\varepsilon}\left[-w+p+\frac{\sigma}{\varepsilon+\eta} u j^{2}\right.
$$

Equation (13) measures the area of the triangle $A B C$ in Figure 1 . In what follows we assume that the objective of policy is to minimize the expected value of the welfare loss, and we denote the loss function by $H$ where $H=E(\Delta) .^{3}$

As is evident by inspection of (13), a policy that is capable of generating a real wage $w-p$ that is equal to the equilibrium wage $\sigma u /(c+n)$, will eliminate the welfare loss. In wha follows we determine the optimal wage-indexation formula that eliminate the welfare loss. We then use the loss function to evaluate the welfare implications of alternative formulae for wage indexation and for money supply rules.

\section{II.2 Optimal Wage Indexation}

As was already indicated it is assumed that due to cost of negotiations nominal wages are set in advance and are adjusted over time according to a simple, time-invariant indexation rule. Let the indexation rule be

$$
\log w_{t}=\log w_{0}+b_{0}\left(\log P_{t}-\log P_{0}\right)+b_{1} u_{t}
$$

Equation (14) specifies the wage at period $t$ as a function of (i) $W_{0}$, the equilibrium wage that is obtained in the absence of shocks, 4 (ii) the percentage deviation of the price from its non-stochastic equilibrium, and 
(iii) the effective real shock u. Expressing the wage rule in terms of lower-case letters, recalling that the effective real shock is composed of productivity and energy-price shocks, i.e., $u=\mu-\lambda q$, and allowing for different coefficients of indexation to $\mu$ and $q$, yields

$$
w=b_{0} p+b_{1} \mu+b_{2} q
$$

Equation (15) specifies an indexation rule by which the nominal wage adjusts in response to the price, $p$, to the productivity shock, $\mu$, and to the energy-price shock, $q$. The optimal values of $b_{0}, b_{1}$ and $b_{2}$ are chosen so as to eliminate the discrepancy between actual and equilibrium real wages. Inspection of the last bracketed term in (13) reveals that the nominal wage which eliminates the welfare loss is

$$
\tilde{w}=p+\frac{\sigma}{\varepsilon+\eta} \mu-\frac{\lambda \sigma}{\varepsilon+\eta} q
$$

where $\mu-\lambda q$ has been substituted for the effective real shock $u$. Thus, the optimal values of the coefficients in the indexation rule (15) are:

$$
\tilde{b}_{0}=1, \quad \tilde{b}_{1}=\frac{\sigma}{\varepsilon+n} \text {, and } \tilde{b}_{2}=-\lambda \tilde{b}_{1} \text {. }
$$

This formulation of the indexation rule is analogous to that of Karni (1983) who showed in the context of a closed economy without energy input that at the optimum the nominal wage must adjust to the price level by an indexation coefficient of unity whereas, in general, its adjustment to the productivity shock differs from unity. ${ }^{5}$

The magnitude of the indexation coefficient $\tilde{b}_{1}$ depends on the structure of the economy as reflected by the elasticities of the demand and 
the supply of labor. For example, a lower elasticity of labor supply raises the absolute values of the optimal coefficients of indexation to the real shocks (i.e. to productivity shocks and to energy-price shocks). When the elasticity of the supply of labor approaches zero, $\tilde{b}_{1}$ approaches $[1 /(1-\lambda)]>1$, and $\tilde{b}_{2}$ approaches $-\lambda /(1-\lambda)$. Likewise, the magnitude of the coefficients of indexation to real shocks depend on the relative share of energy cost in output. As seen in equation (16), a higher share of energy cost raises $\tilde{b}_{1}$ as well as the absolute values of $\tilde{b}_{2}$. In general, $\tilde{b}_{1}$ will be positive and $\tilde{b}_{2}$ will be negative.

The key point to emphasize is that by altering the nominal wage the optimal indexation rule eliminates the welfare loss associated with the distortion to the real wage. The equilibrium that is obtained with optimal indexation replicates the equilibrium that would have been obtained if labor market cleared after the realization of the stochastic shocks. Thereby, the optimal indexation formula serves to nullify the distortions arising from the assumption that, because of contracts, nominal wages are predetermined. 6 Further, if economic policy was only concerned with the efficiency of resource allocation then, in the absence of other distortions, once the optimal indexation formula is adopted there is no need to undertake additional macroeconomic policies.

The essense of the optimal indexation rule lies in the separation between the coefficients of indexation to nominal and to real shocks. In the specification of equation (14), nominal shocks were represented by $p$ and real shocks were represented by $u$. It was shown that with optimal indexation wages should be indexed to $p$ with a coefficient of unity whereas the magnitude of the optimal indexation to $u$ depends on the elasticities of the demand and the supply of labor. Since ultimately the real shocks are manifested in the realized level of output, we may also 
include the level of output directly in the indexation rule and, thereby, obtain an alternative formulation. The alternative formulation expresses the wage indexation rule in terms of the response of nominal wages to the price and to the level of output. Accordingly,

$$
w=p+b_{y} y
$$

where $b_{y}$ denotes the coefficient of indexation of nominal wages to real output. Substituting $b_{y} y$ for $(w-p)$ in $\left(6^{\prime}\right)$ yields the realized value of $y$, and equating this realization with the equilibrium value $\bar{y}$ from equation (10), yields the optimal indexation coefficient:

$$
\tilde{b}_{y}=\frac{1}{1+\varepsilon}
$$

Thus, the optimal indexation rule expressed in terms of prices and output is:

$\left(17^{\prime}\right) \quad w=p+\frac{1}{1+\varepsilon} y \quad{ }^{7}$

The advantage of this alternative (but equivalent) formulation is its simplicity. Here the wage rule is specified in terms of the observable variables $p$ and $y$ about which data are readily available.

III. Alternative Wage Indexation Rules

In the previous section we specified the optimal wage indexation formula. In this section we apply the analytical framework to an evaluation of specific proposals for indexation rules including the indexation of nominal wages to nominal income, to the consumer price index (CPI) and to 
the domestic value-added price index. ${ }^{8}$ In general, restoration of labor market equilibrium in response to some shocks necessitates some adjustment of employment and some adjustment of real wages. The optimal indexation formula provides for the optimal division of the adjustment between changes in employment and changes in real wages. The various proposals which depart from the optimal indexation rule differ in terms of the allocation of adjustment between employment and real wages. In order to evaluate the relative merits and welfare costs of such alternative allocations of adjustment we start with an analysis of two extreme indexation rules -- a rule that stabilizes the real wage and a rule that stabilizes employment. In general, the various proposals for wage rules involve some combination of the two extreme rules. Tnerefore, the analysis of the two extreme cases provides the necessary ingredients for an evaluation of the various proposals.

\section{III.1 Stable Real Wages Versus Stable Employment}

Generally, as was shown before, the expected welfare loss, $H$, is proportional to the expected squared discrepancy between the actual wage and the equilibrium real wage:

$$
H=a E[-(w-p)+(w-p)]^{2}
$$

where a denotes the proportionality factor implied by equation (13). Consider first the indexation rule that stabilizes the real wage. With this indexation rule $w-p=0$. Substituting the equilibrium real wage from equation (9) into (18) implies that in this case the welfare loss is

$$
H_{W=p}=a\left(\frac{o}{\varepsilon+n}\right)^{2} \sigma_{u}^{2}
$$


In equation (19) $H_{W=p}$ indicates that this loss results from the stabilization of real wages. Thus, equation (19) shows the welfare loss resulting from an indexation rule by which nominal wages are indexed to the CPI with a coefficient of unity.

Consider next the other extreme indexation rule which stabilizes employment and thereby ensures that $\ell=0$. In that case it follows from equation (4') that the actual real wage is $u /(1-\lambda)$. Substituting into (18) implies that with $\ell=0$ the welfare loss is

$$
H_{l=0}=a E\left[-\frac{u}{1-\lambda}+\frac{\sigma u}{\varepsilon+\eta}\right]^{2}=a\left[\frac{\varepsilon}{(1-\lambda)(\varepsilon+\eta)}\right]^{2} \sigma_{u}^{2}
$$

where the notation indicates that this welfare loss results from the stabilization of employment.

These two measures of the welfare cost are described diagramatically in Figure 2. The schedules $\ell^{d}$ and $\ell^{s}$ portray the demand and the supply of labor as specified by equations ( $4^{\prime}$ ) and ( $7^{\prime}$ ) in section $I$. The slopes of $\ell^{d}$ and $\ell^{\mathrm{s}}$ are $-1 / n$ and $1 / \varepsilon$, respectively, that is, the slopes are the inverse of the corresponding elasticities. The initial equilibrium is described by point 0 at which, the initial demand curve (not drawn) intersected with the supply. Thus, initially, $\left(w^{-} p\right)=0$. The demand schedule drawn in Figure 2 corresponds to a situation in which there was a positive realization of the effective real shock, $u$. As indicated by equation ( $4^{\prime}$ ), this shock induces an upward displacement of the demand schedule by $u /(1-\lambda)$ and results in a new equilibrium real wage $\sigma u /(\varepsilon+\eta)$ and, correspondingly, in a new equilibrium level of employment.

When the indexation rule stipulates that real wages must not change the real wage remains at point 0 and employment increases to $l_{q}$ at point 


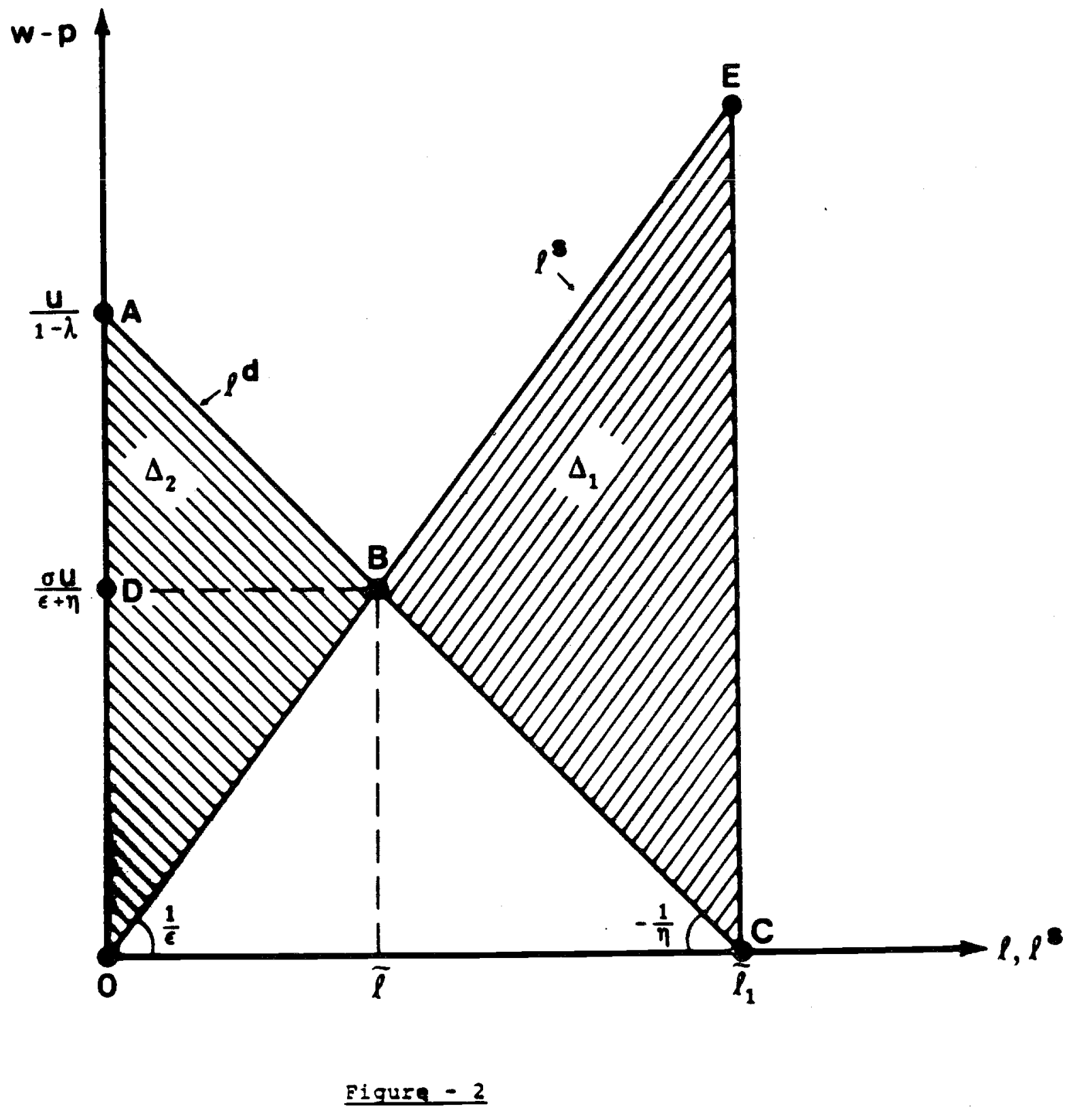


C. In that case the welfare loss is proportional to the area of the triangle CEB, and its expected value is $H_{W=p}$ as specified by equation (19). In the other extreme, when the indexation rule stipulates that employment must not change, the level of employment remains at point 0 and the real wage rises to $u /(1-\lambda)$ at point $A$. In that case the welfare loss is proportional to the area of the triangle $O A B$, and its expected value is $H_{Z=0}$ as specified by equation (20). Since the various expressions relate to percentage deviations from the non-stochastic equilibrium, the actual welfare loss expressed in units of output is obtained by multiplying (19) and $(20)$ by the equilibrium non-stochastic wage bill.

In order to determine the relation between the extent of the welfare losses in the two cases we need to compare the areas of the two triangles CEB (denoted by $\Delta_{1}$ ) and $O A B$ (denoted by $\Delta_{2}$ ). We first note from the geometry that the two triangles are similar and that the ratio AD/DO (where point $D$ inaicates the equilibrium real wage) equals the ratio $A B / B C$. It foilows, therefore, that the ratio of the two areas $\Delta_{2} / \Delta_{1}$ equals $(A D / D O)^{2}$. As seen in Figure 2,

$$
\begin{aligned}
& A D=\left(\frac{1}{1-\lambda}-\frac{\sigma}{\varepsilon+n}\right) u=\frac{\sigma \varepsilon}{n(\varepsilon+n)} u \quad \text { and } \\
& D O=\left(\frac{\sigma}{\varepsilon+n}\right) u \quad ;
\end{aligned}
$$

therefore,

$$
\frac{\Delta_{2}}{\Delta_{1}}=\left(\frac{\varepsilon}{n}\right)^{2}
$$

Thus, if the elasticity of labor supply, $\varepsilon$, is smaller than the elasticity of labor demand, $\eta$, then an indexation rule that fixes employment induces 
a lower welfare loss than an indexation rule that fixes the real wage. Tnis is the case illustrated in Figure 2. On the other hand if the elasticity of the supply of labor exceeds the elasticity of the demand, $\Delta_{2}>\Delta_{1} ;$ under such circumstances rules which stabilize employment inflict higher welfare cost than rules which stabilize the real wage.

The preceeding analysis of the two extreme indexation rules provides the ingredients necessary for the evaluation of various proposals which combine elements of the two extreme rules. We turn next to examine the properties of the proposal of linking the nominal wage to nominal income.

\section{III.2 Indexation to Nominal Income}

When the nominal wage is indexed to nominal income with a unit coefficient, $w=p+y$. In this case the coefficients of indexation to the price and to real output are both unity. We first note with reference to equation (17') that as long as the elasticity of the supply of labor, $E$, differs from zero, full indexation to nominal income entails welfare loss. Only when $\varepsilon=0$ the optimal indexation rule requires that wages be indexed to nominal income with a coefficient of unity.

In order to evaluate the welfare cost induced by the deaprture from the optimal indexation rule, we note that with indexation to nominal income, $w-p=y$. Substituting $w-p$ for $y$ in (6') and solving for the realized real wage yields:

$$
\left.(w-p)\right|_{w=p+y}=\frac{1}{1-\lambda} u
$$

where the notation in (22) indicates that this wage is obtained under the rule by which nominal wages are indexed to nominal income with a coefficient 
of unity. With this real wage the level of employment can be read from equation (4'). Substituting (22) for the real wage in equation (4') shows that in this case $\ell=0$. Thus, an indexation rule that links the nominal wage to nominal income through an indexation coefficient of unity results in stable employment. The resulting welfare loss corresponds to the area of the triangle $O A B$ in Figure 2 and is expressed by equation (20). Thus it follows that

$$
H_{w=p+y}=H_{l=0}
$$

\section{III.3 Indexation to the Value-Added Price Index}

An alternative proposal which received wide attention especially following the energy shocks of the 1970's links wages to the domestic valueadded price index. This proposal was analysed recently by Marston and Turnovsky (1983). In what follows we explore further the implications of such an indexation rule.

Let the price of final output $p$ be a weighted average of the domestic value-added price index, $p_{d}$, and the price of imported energy input $p_{v}$, and let the weights correspond to the relative shares of value added and energy in output. Thus

$$
p=(1-\lambda) p_{d}+\lambda p_{v}
$$

It follows that the domestic value-added price index is

$$
p_{d}=\frac{1}{1-\lambda} p-\frac{\lambda}{1-\lambda} p_{y}
$$


An indexation rule which links the nominal wage to this index through a coefficient of unity, sets $w=p_{d}$. By using the definition of $p_{d}$ from (24), the implied real wage is

$$
\left.(w-p)\right|_{w=p_{d}}=-\frac{\lambda}{1-\lambda} q
$$

where the notation indicates that tnis wage is obtained under the rule by which nominal wages are indexed to $p_{d}$ with a coefficient of unity. A comparison between equations (25) and (22) reveals that in the special casefor which $\mu=0$ (so that shocks to the imported energy price constitute the only component of the effective real shock) then $u=-\lambda q$ and the indexation of wages to the domestic value-added price index is equivalent to the indexation of wages to nominal income. Furthermore, as was shown before, in this case such indexation results in stable employment and the corresponding welfare loss is also represented by equations (20).

In the more general case, however, with non-zero productivity shocks the indexation to $p_{d}$ does not stabilize employment and the welfare loss differs from the one represented by equations (20). The expression for the welfare cost in that case is obtained by substituting the equilibrium real wage from (9) and the actual real wage from (25) into (18). Accordingly,

$$
H_{w=p_{d}}=a\left[\frac{\varepsilon}{(1-\lambda)(\varepsilon+n)} j^{2} \lambda^{2} \sigma_{q}^{2}+a\left[\frac{n}{(1-\lambda)(\varepsilon+n)}\right]^{2} \sigma_{\mu}^{2}\right.
$$

where the notation indicates that this welfare loss results from adopting the rule by which nominal wages are indexed to $\mathrm{p}_{\mathrm{d}}$ with $a$ coefficient of unity. 


\section{III.4 Ranking the Indexation Rules}

The preceeding discussion implies that, in general, the choice between indexation to nominal income and to the domestic value-added price index depends on the difference between the expressions measuring the losses $H_{w=p_{d}}($ in $(26))$ and $H_{\ell=0}$ (in (20)). In order to facilitate such comparison it is useful to rewrite equation (20) somewhat differently by decomposing the effective real shock into its two components. Tnus,

(20, ) $\quad H_{\ell=0}=a\left[\frac{\varepsilon}{(1-\lambda)(\varepsilon+n)}\right]^{2}\left(\sigma_{\mu}^{2}+\lambda^{2} \sigma_{q}^{2}\right)$.

Since the terms involving the variance of $q$ are identical in both of the expressions in (26) and (20'), differences in the welfare cost arise only from the terms involving the variance of $\mu$. Subtracting (20') from (26) and denoting the difference by $D$ yields

$$
D=\frac{a\left(n^{2}-\varepsilon^{2}\right)}{\lfloor(1-\lambda)(\varepsilon+n)\rfloor^{2}} \text {. }
$$

Thus, the sign of $D$ depends on whether the elasticity of the demand for labor exceeds or falls short of the corresponding elastlcity of supply. Since $\eta=(1-\lambda) \sigma$ exceeds unity (in practice, with typical relative snares, the magnitude of $n$ is likely to be around 3 ), and since estimates of the elasticity of labor supply are typically small, it seems that indexation to nominal income is likely to be preferable to indexation to the domestic value-added price index. The opposite holds, however, for cases in which the elasticity of supply exceeds the elasticity of demand.

A comparison boiween (20') and (26) shows that when $\varepsilon=0$, indexation to nominal income is optimal since in that case the value of the loss 
function in (20') is zero. In contrast, as shown in equation (26), the welfare loss associated with indexation to the domestic value-added price index is positive even though $\varepsilon=0$. In this case, the expression in (26) is reduced to $a[1 /(1-\lambda)]^{2} \sigma_{\mu}^{2}$. As argued before, only when the variance of the productivity shock, $\mu$, is zero the two indexation rules yield identical outcomes. 9

In order to gain a broader perspective over the issues involved in the comparison between the two forms of indexation we note that the condition determining the sign of $D$ in (27) is the same as the condition determining whether the cost of indexation rules that stabilize the real wage exceeds or falls short of the cost of indexation rules that stabilize employment. These relative costs are reflected in the relative sizes of the triangles in Figure 2. As shown in equation (21) when the elasticity of the demand for labor exceeds the elasticity of supply indexation rules that stabilize employment are preferable to those that stabilize real wages. Those are also the circumstances under which the indexation of wages to nominal income is preferable to indexation to the domestic value-added price index.

The equivalence between the condition under which stable employment is preferable to stable real wages and the condition under which indexation to nominal income is preferable to indexation to the value-added price index is interpreted by reference to equations (22) and (25). When wages are indexed to the value-added price index then, as seen in equation (25), any given realization of the productivity shock, $\mu$, does not alter the real wage. Therefore, when the effective real shock consists only of productivity shocks this rule stabilizes the real wage. On the other hand when wages are indexed to nominal income then, as seen in equation (22), any given realization of the productivity shock alters the real wage by 
$\mu /(1-\lambda)$. This change in the real wage corresponds precisely to the vertical displacement of the demand for labor arising from the productivity shock and, therefore, results in stable employment. Finally, as indicated above, when the effective real shock consists only of shocks to the price of imported energy then, as seen from equations (22) and (25), the two rules yield identical outcomes in terms of real wages, employment and welfare.

The following analysis of the various wage indexation rules is summarized in Table 1 . In it we report the coefficients of indexation to the price $\left(b_{0}\right)$, to the productivity shock $\left(b_{1}\right)$ and to the energy-price shock $\left(\mathrm{b}_{2}\right)$ that are implied by the alternative indexation rules. For example, when wages are indexed to $p_{d}$ then, as indicated by the second line of Table 1 , such a rule implies an indexation to $p$ with a coefficient $b_{0}=1$ and an indexation to $q$ with a coefficient $b_{2}=-\lambda /(1-\lambda)$. This rule follows from equation (25). Likewise, the third line of Table 1 specifies the coefficients implied by an indexation rule by which nominal wages are indexed to nominal income with a coefficient of unity. These coefficients follow from equation (22). The optimal indexation formula corresponds to the final line in the Table that follows from equation (16).

Our analysis also determined the welfare cost associated with the various indexation rules. Accordingly, as shown in Table 1, if the elasticity of the supply of labor is smaller than the elasticity of the demand, then the welfare ranking of the alternative rules is

$$
\tilde{b} \succ p+y \succ p_{d}>p
$$

where the symbol $x>y$ indicates that $x$ is prefered to $y$. Thus, it follows that under this assumption full indexation to nominal income is prefered to full indexation to the domestic value-added price index which, 
TABLE 1

ALTERNATIVE WAGE RULES

$w=b_{0} p+b_{1} \mu+b_{2} q$

\begin{tabular}{|c|c|c|c|}
\hline \multirow[b]{2}{*}{$\begin{array}{c}\text { Wages } \\
\text { Indexed to } \\
\end{array}$} & \multicolumn{3}{|c|}{ Indexation Coefficients } \\
\hline & $\mathrm{b}_{\mathrm{o}}$ & $\mathrm{b}_{1}$ & $\mathrm{~b}_{2}$ \\
\hline $\operatorname{CPI}(p)$ & 1 & 0 & 0 \\
\hline $\begin{array}{l}\text { Value-added } \\
\text { deflator }\left(\mathrm{p}_{\mathrm{d}}\right)\end{array}$ & 1 & 0 & $-\frac{\lambda}{1-\lambda}$ \\
\hline $\begin{array}{l}\text { Nominal } \\
\text { income }(p+y)\end{array}$ & 1 & $\frac{1}{1-\lambda}$ & $-\frac{\lambda}{1-\lambda}$ \\
\hline $\begin{array}{l}\text { Optimal } \\
\text { Indexation } \\
\qquad(\tilde{b})\end{array}$ & 1 & $\frac{\sigma}{\varepsilon+n}$ & $\frac{-\lambda \sigma}{\varepsilon+\eta}$ \\
\hline
\end{tabular}

Conclusion: If $\varepsilon<\eta$ then the welfare ranking of the alternative rules is: $\tilde{\mathrm{b}} \succ \mathrm{p}+\mathrm{y} \succ \mathrm{p}_{\mathrm{d}} \succ \mathrm{p}$, and if $\varepsilon>\eta$ then the welfare ranking is $\tilde{b} \succ p \succ p_{d} \succ p+y$. 
in turn, is prefered to full indexation to the CPI. Of course, the optimal indexation rule, $\vec{b}$, is prefered to all of the other alternatives. On the other hand, for cases in which the elasticity of the supply of labor exceeds the elasticity of the demand, the welfare ordering of the sub-optimal rules is reversed. In that case

\section{(28, $\quad \tilde{b}>p>p_{d}>p+y$}

IV. Monetary Equilibrium and Optimal Accommodation

Up to this point the monetary sector has played no explicit role in the analysis of the wage-indexation rules. Detailed considerations of the money market could be left in the background since in all the rules that we have examined, wages were indexed to the CPI with a coefficient of unity. Furthermore, as shown in Aizenman and Frenkel (1985), the specification of the model implies that there is a redundancy of policy instruments. Therefore, in the absence of other distortions, once the optimal indexation rule is adopted there is no need to undertake additional macroeconomic policies. On the other hand it also follows that if wages are not indexed optimally then there may be room for other policies aiming at the restoration of labor market equilibrium. In this section we introduce the monetary sector and analyse the optimal money supply rule.

\section{IV.I The Monetary Sector}

In order to determine the equilibrium levels of the nominal quantities like the price level we need to introduce the conditions of money market equilibrium. Let the demand for money be

$$
\log M_{t}^{d}=\log k+\log P_{t}+\xi \log y_{t}-\alpha i_{t}
$$


where $M$ denotes nominal balances, i denotes the nominal rate of interest and $\alpha$ denotes the (semi) elasticity of the demand for money with respect to the rate of interest and $\xi$ denotes the income elasticity of the demand. The domestic price level is assumed to be linked to the foreign price through purchasing power parity. Thus,

$$
\log P_{t}=\log S_{t}+\log P_{t}^{\prime}
$$

where $S_{t}$ denotes the exchange rate (the price of foreign currency in terms of domestic currency), and $P_{t}^{\prime}$ denotes the foreign price. Let the foreign price be

(31) $\quad \log P_{t}^{\prime}=\log \bar{P}^{\prime}+x_{t}$

where a prime (') denotes a foreign variable and where a bar over a variable denotes the value of its fixed component. In equation (31), $x_{t}$ denotes the stochastic component of the foreign price which is assumed to be distributed normally with zero mean and a fixed known variance. Using (31) for $\log P_{t}^{\prime}$ yields

$$
\log P_{t}=\log S_{t}+\log \bar{P}^{\prime}+x_{t}
$$

In principle, the random component of $P_{t}$ may also include stochastic deviations from the purchasing power parity relation of equation (32). When all shocks are zero, the domestic price is:

(32') $\log P_{0}=\log S_{0}+\log \bar{P}^{\prime}$ 
and subtracting $\left(32^{\prime}\right)$ from (32) yields

$$
p=s+x
$$

where, as before, we suppress the time subscripts.

The nominal rate of interest is linked to the foreign rate of interest, i'. Arbitrage by investors, who are assumed to be risk neutral, assures that uncovered interest parity holds:

$$
i_{t}=i_{t}^{\prime}+E_{t}\left(\log S_{t+1}-108 S_{t}\right)
$$

where $E_{t} \log S_{t+1}$ denotes the expected exchange rate for period $t+1$ based on the information available at period $t$. The foreign rate of interest is also subject to a random shock, $\rho$, which is distributed normally witn zero mean and a fixed known variance. Thus,

$$
i_{t}^{\prime}=\bar{i}+p_{t}
$$

The specification of the stochastic shocks imply that the expected exchange rate for period $t+1$ is $S_{0}$ (the level obtained in the absence of shocks) and, therefore, $E_{t}\left(\log s_{t+1}-\log s_{t}\right)=-s_{t}$. Thus, using equations (34)(35), it follows that

(36) $\quad i_{t}-\bar{i}=p-s \cdot 10$

In the absence of stochastic shocks $i=\vec{i}$, and, therefore,

$$
\text { (29') } \quad \log M_{0}^{d}=\log K+\log P_{0}+\xi \log y_{0}-a \bar{i} \cdot
$$


Subtracting (29') from (29), omitting the time subscript and recaling that from (33) $s=p-x$ yields

$$
m^{d}=(1+\alpha) p+\xi y-\alpha(\rho+x)
$$

The supply of money (or more precisely, the percentage deviation of the supply of money from its non-stochastic level) is denoted by $m$. Monetary equilibrium is obtained when the demand for money equals the supply. We turn next to an analysis of the optimal money supply.

\section{IV.2 Optimal Monetary Policy}

The analysis of section Il derived the optimal wage-indexation rule. In this section we focus on the determinants of a money-supply rule that is designed to achieve the same goal of elinimating labor-market disequilibrium. In order to determine the optimal money supply and to contrast the results with those of the previous sections, we assume that wages are completely unindexed so that $w=0$. The question that is being addressed concerns the optimal response of monetary policy in the face of exogeneously given shocks. This question is not new. It was addressed by various authors in the context of the energy supply shocks of the 1970's. ${ }^{11}$ The key question was whether monetary policy should be accommodative and expend the money supply in order to "finance" the higher energy price or whether it should be anti-accommodative and contract the money supply in order to lower inflation. It has of course been recognized that a real shock which lowers the potential level of output can not be combated successfully by monetary policy. The question was whether monetary policy could be designed so as to prevent the additional costs arising from departures from the new (lower) level of potential output. In what follows we reexamine this question. 
In order to determine the optimal money supply we first equate the demand for money $\mathrm{m}^{\mathrm{d}}$ (from 37) with the supply $\mathrm{m}$ and, by using equation (10) for the equilibrium level of output, we obtain the equilibrium price level $\overline{\mathrm{p}}$ :

$$
\tilde{p}=\frac{1}{1+\alpha}\left\lfloor m+\alpha(p+x)-\frac{(1+\varepsilon) \xi \sigma}{\varepsilon+\eta} u\right\rfloor \quad .
$$

From equation (9) it is evident that when $w=0$ (as is the case when nominal wages are unindexed), the value of $p$ which yields the equilibrium real wage and thereby eliminates labor market disequilibrium is

(9') $\quad \bar{p}=-\frac{\sigma}{\varepsilon+\eta} u$.

Equating the value of $p$ which clears the money market (from equation (38)) with the corresponding value of $p$ which clears the labor market (from equation $\left(9^{\prime}\right)$ ) and solving for $m$ yields the optimal monetary rule

$$
\bar{m}=-\alpha(p+\chi)+\frac{[\xi(1+\varepsilon)-(1+\alpha)] \sigma}{\varepsilon+\eta}(\mu-\lambda q)
$$

where $\mu-\lambda q$ has been substituted for the effective real shock $u$. Inspection of equation (39) reveals that when the income elasticity of the demand for money, $\xi$, is unity, while the elasticity of the supply of labor, $\varepsilon$, and the (semi) interest elasticity of the demand for money, $\alpha$, are zero then $\tilde{m}=0$. Tnis is the case analysed in detail by Fischer (1985). In this special case the price generated by the condition of money market equilibrium is precisely the price needed to yield the equilibrium real wage and, therefore, no accommodation is necessary. In fact, any attempt to alter the money supply in response to the supply shock would result in 
suboptimal employment and would inflict welfare loss. In general, however, as long as $\alpha$ or $\varepsilon$ differ from zero and $\xi$ differs from unity, there is room for active monetary policy. ${ }^{12}$

In interpreting the rule specified by (39) we note that a positive foreign interest rate shock, $\rho$, as well as a positive foreign price shock, $x$, lower the demand for money; the interest shock operates through its direct effect on the domestic rate of interest while the price shock operates through its impact on exchange rate expectations. When both shocks are present, their impact is to reduce the demand for money by $a(\rho+x) .^{13}$ The proper response should reduce the money supply by the same amount and, thereby, prevent further spill-overs of the effects of these snocks to other segments of the economy. The second term on the right-hand-side of equation (39) specify the optimal response to shocks to productivity, $\mu$, and to the imported energy price, q. Both of these shocks alter the equilibrium level of output and result in a new equilibrium real wage. In addition, the new equilibrium level of output alters the demand for money. Without changes in the money supply, the conditions of money market equilibrium yield a new price level and, thereby, a new real wage. As shown in equation (39) the induced change in the real wage will be just sufficient to restore labor market equilibrium only if $\xi(1+\varepsilon)$ equals $(1+\alpha)$. In general, a rise in the price of imported energy should induce an expansionary monetary policy if $(1+\alpha)>\xi(1+\varepsilon)$, and vice versa. It is also relevant to note that in general the optimal monetary response to the effective real shock depenas on the relative share of imported energy in output. A higher value of the energy share, $\lambda$, raises the (absolute value of) the optimal response.

The preceeding analysis demonstrated that when wages are unindexed monetary policy could be designed to ensure labor market equilibrium. Furthermore, it was shown that when $\xi=1$ and $\varepsilon=\alpha=0$ monetary policy should 
not accommodate supply shocks. Prior to concluding this section it is worth reexamining these results for situations in which wages are indexed according to an arbitrary rule by which $w=b_{0} p$. Recalling the equilibrium real wage from equation (9) and using the assumed indexation rule, yields the equilibrium price which clears the labor market

$(9+1) \quad \bar{p}=-\frac{\sigma}{\left(1-b_{0}\right)(\varepsilon+n)} u \quad$.

Following the same procedure as before we equate this price with the price that clears the money market and obtain the optimal money supply rule

(39') $\quad \tilde{m}=-\alpha(p+\chi)+\frac{\left[\xi\left(1-b_{0}\right)(1+\varepsilon)-(1+\alpha) j \sigma\right.}{\left(1-b_{0}\right)(\varepsilon+n)}(\mu-\lambda q)$.

Two points are worth noting with reference to equation $\left(39^{\prime}\right)$. First, in contrast with the discussion of equation (39) where nominal wages were unindexed, here even if $\xi=1$ and $\varepsilon=\alpha=0$, $\bar{m}$ does not equal zero, and a real shock calls for an active monetary response. In that case the optimal money supply rule becomes

$(39 \cdots) \quad \tilde{m}=\frac{-b_{0}}{\left(1-b_{0}\right)(1-\lambda)}(\mu-\lambda q) \quad$

Thus, with a partial wage indexation a rise in the price of energy and a negative productivity shock require an expansionary monetary policy.

Second, with one important exception, the welfare cost induced by the choice of a sub-optimal value of $b_{0}$ could be eliminated through the monetary rule prescribed by equation $\left(39^{\circ}\right)$. The important exception occurs 
when $b_{0}$ is set arbitrarily to equal unity. In that case the indexation rule prevents changes in the real wage and results in an absolute real-wage rigidity. Therefore, any real shock that alters the equilibrium real wage results in labor market disequilibrium and induces welf are cost. Monetary policy can not reduce this cost.

\section{IV.3 Alternative Monetary Rules}

The preceeding discussion specified the optimal money-supply rule. In practice, various alternative rules for monetary targets have been proposed, with special attention given recently to the proposal that monetary policy targets nominal income. 14 In this section we apply the analytical framework to the evaluation of alternative proposals. For this purpose we substitute equation ( $\left.6^{\prime}\right)$ for $y$ into the demand for money (equation (37)) and recalling that with zero wage indexation $w=0$, the demand for money can be written as

(37') $\quad m^{d}=(1+\alpha+\xi \sigma \beta) p+\xi \sigma u-\alpha(\rho+x)$.

Consider first a monetary rule that targets the CPI. With such a rule $p=0$ in equation $\left(37^{\circ}\right)$, and the resulting money supply is

$$
m_{p=0}=\xi \text { ou }-\alpha(\rho+x)
$$

This monetary rule assures that $p=0$ and, in the absence of wage indexation, the real wage is stabilized. The welfare loss associated with CPI targeting is the same as the loss resulting from a full indexation of wages 
to the CPI since both stabilize the real wage. This loss is specified in equation (19).

Consider next the monetary rule which targets nominal income. Witn such a rule $p+y=0$. In this case, using equation (6'), the value of output is $y=\sigma u /(1+\bar{b} 0)$. Substituting into equation (37') and recalling that $p=-y$, the resulting money supply is

(41)

$$
\mathrm{m}_{\left.\right|_{p+y=0}}=\frac{\lfloor\xi-(1+\alpha)\rfloor \sigma}{1+\beta \sigma} u=\frac{[\xi-(1+\alpha)\rfloor}{1-\lambda} u
$$

In order to evaluate the : =lfare loss associated with this monetary rule we note that in this case, with $w=0$, the real wage $(w-p)$ equals $y$ and, using (6') $y=[1 /(1-\lambda)] u$. With this real wage the level of employment remains unchanged (as seen from equation (4')) and, therefore, the resulting welfare loss is specified in equation (23).

Consider next a third monetary rule which targets the domestic value-added price index. With this rule $p_{d}=0$ and, using the definition of $p_{d}$ form $(24)$, it follows that $p=\lfloor\lambda /(1-\lambda)\rfloor q$. Substituting into $\left(37^{\prime}\right)$ the resulting money supply is

(42) $\quad m_{p_{d}=0}=\xi \sigma \mu-\frac{[\xi-(1+\alpha)]}{1-\lambda} \lambda q-\alpha(p+x)$.

With this targeting rule and with unindexed wages, $w=p_{d}=0$ and the resulting welfare loss is specified by equation $(26)$.

Tne equivalence between the measures of the welfare cost associated with the targeting rules for monetary policy and the indexation rules for nominal wages implies that the welfare rankings of the various rules is also 
the same as those in equations $(28)-\left(28^{\circ}\right)$. It follows that if $\varepsilon<n$, the welfare ranking is

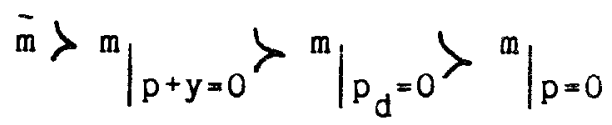

and, if $\varepsilon>n$, the welfare ranking is

(43') $\quad \bar{m}>\left.m_{p_{p=0}} \succ m_{p_{d}=0} \succ m\right|_{p+y=0}$

It is interesting to note that the ranking provided by (43) is aiso consistent with that in Tobin (1983) where the targeting of nominal income (with annual revisions) is supported and the targeting of price indexes is criticized. However, in discussing the choice between targeting $p$ and targeting $p_{d}$ Tobin concludes that

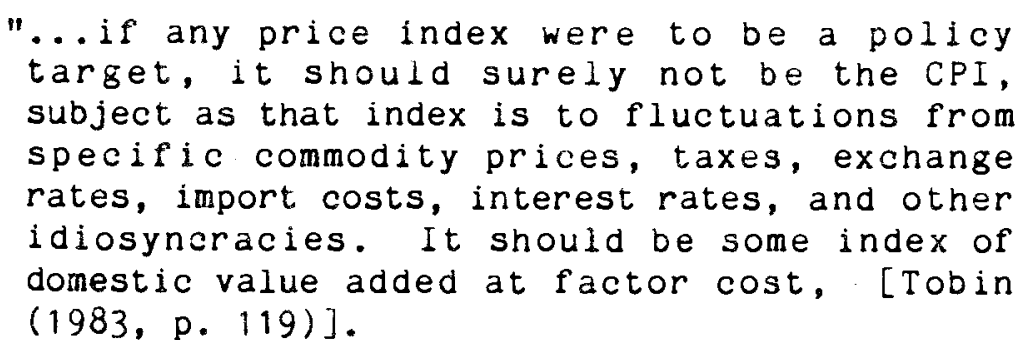

Our analysis shows that this ranking is not robust. As revealed by the comparison of (43) with (43'), the ranking of the various alternatives depends on the relative magnitudes of the elasticities of the demand and the supply of labor.

In this section we have considered three specific targeting rules. A similar procedure can be applied to the evaluation of other rules like targeting the exchange rate (e.g., setting $s=0)$, targeting the interest rate (e.g., setting $i-\bar{i}^{\prime}=0$ ) targeting the money supply (e.g., setting $m=0$ ), or 
Hall's (1984) "elastic price rule". Each of these alternatives inflicts welfare cost but, in general, the welfare ranking of the various rules depends on the values of the parameters. It can be shown, however, that

$$
m_{p=0}>\left.m\right|_{s=0}>\left.m\right|_{i-i \cdot=0}
$$

Thus, in the present model, a monetary rule that targets the CPI produces smaller welfare costs than a rule that targets the exchange rate which, in turn, has smaller costs than a mle that targets the rate of interest. Furthermore, in the special case for which $\varepsilon=0$, the targeting of nominal GNP is optimal and, therefore, it dominates the other policy rules including the constant money-growth rule.

Finally, it is relevant to note that when there are no real shocks so that $\mu=q=y=0$, then, $p+y=p=p_{d}$. In this special case all of the targeting rules (including the optimal rule, $\tilde{m}$ ) yleld identical moneysupply response. This response ensures that the real wage remains intact, that changes in the money supply exactly offset shocks-induced changes in the money demand, and that the welfare cost is eliminated.

V. Concluding Remarks

In this paper we analysed the interactions among supply shocks, wage indexation and monetary policy. We developed an analytical framework for the determination of optimal wage indexation and monetary policy. This framework was then applied to the analysis of the implications of suboptimal policy rules. The welfare ranking of these rules was based on the relative magnitudes of the dead-weight losses associated with the various 
policies. The main results of our analysis are summarized in the introduction to this paper. In what follows we outline some of the limitations and further extentions.

In our framework labor-market contracts stipulate the nominal wage rule for the length of the contract period. These contracts reflect the cost of negotiations. Since the wage rule is set in advance of tine realization of the stochastic shocks, it may give rise to dead-weight losses associated with disequilibrium real wages. Our analysis employs this specific form of wage contracts as a stylized description of conventional labormarket arrangements. Implicit in our formulation is the assumption that workers and employers are risk neutral. A useful extension would allow for risk aversion which would rationalize contracts in terms of the insurance function [see, for example, Azarariadis (1978)].

Further, in our specification the welfare loss arises only from suboptimal employment level. Implicit in this specification is the assmumption that all other markets are undistorted. An extension would allow for other distortions. In that case the welfare loss due to sub-optimal money holdings would be added to the loss associated with labor-market distortions and would depend on both the level and the variance of inflation.

While we have assumed in the main analysis that the stochastic shocks are identically and independently distributed with a zero mean and a fixed variance, we have outlined the way by which one could allow for more general time-series properties of the stochastic shocks. An explicit elaboration of such on extension would highiight the important distinction between permanent and transitory shocks, and would generate a profile of wage dynamics. Richer and more complicated dynamics could also be induced by staggered contracts and by capital accumulation [see, for example, Fischer $(1977 \mathrm{c}, 1985)$ and Taylor $(1980)]$. 
Our analysis assumed that there is one composite good which is traded internationally at a (stochastically) given world price. With this level of aggregation we demonstrated that wage-indexation rules bear an exact dual relation to monetary-targeting rules. This duality implied that there was no fundamental difference between the outcomes of various wageindexation rules and the outcomes of the corresponding monetary-targeting rules. Therefore, when there is a single composite commodity the choice between wage indexation and monetary policy is governed by additional considerations like the relative costs and complexities associated with the implementation of the two alternatives rules. In the more general case, however, when there are many sectors producing a variety of goods, the exact duality between wage indexation and monetary policy breaks down. Specifically, as shown by Blinder and Mankiw (1984), it is elear that monetary policy, being an aggregative policy, is not suitable for dealing with sector-specific snocks. Under such circumstances it is evident that optimal sector-specific policies are called for. A natural extension of our analysis would apply the analytical framework to the determination of the optimal sector-specific wage-indexation formulae that would eliminate the welfare loss resulting from labor-market distortions. 


\section{APPENDIX}

\section{The Computation of the Welfare Loss}

In this Appendix we provide a formal derivation of the welfare loss that is used in the text.

Consider a two-period model and let the present value of utility $U$ be:

$(A-1) \quad U=u\left(C_{1}, L_{1}\right)+\tilde{\rho} u\left(C_{2}, L_{2}\right)$

where $\tilde{\rho}$ designates the subjective discount factor, $C_{i}$ and $L_{i}(i=1,2)$ denote the levels of consumption and labor in period $i$ and where the subscripts 1 and 2 designate periods 1 and 2 respectively. The value of assets which are not consumed in period 1 is $A$, and their value in period 2 is $(1+r) A_{1}$ where $r$ designates the exogenously given (stochastic) world rate of interest on internationally traded bonds. Profits are denoted by $R$ and are assumed to be redistributed as lump-sum transfers. The value of profits in each period is the corresponding value of output, $Y_{t}$, minus payments to labor and energy inputs:

$(A-2)$

$$
R_{t}=Y_{t}\left(L_{t}, V_{t}\right)-\left(\frac{W}{P}\right)_{t} L_{t}-\left(\frac{P}{P}\right)_{t} V_{t}, \quad(t=1,2)
$$

where $W, P_{v}$ and $P$ denote the nominal wage, the price of energy and the price of output, respectively. Producers are assumed to maximize profits 
subject to the given real wage and the given relative price of energy. In equilibrium the real wage and the relative price of energy are equated to the marginal products of labor and energy, respectively.

$$
\frac{\partial Y(L, V)}{\partial L}=\frac{W}{P}
$$

$(A-4)$

$$
\frac{\partial Y(L, V)}{\partial V}=\frac{P}{P}
$$

These conditions yield the demands for labor and energy inputs. The equilibrium real wage that clears the labor market is defined by $(\tilde{W} / P)$ and $\tilde{L}$ and $\tilde{V}$ denote the corresponding equilibrium levels of employment and energy utilization. At this general equilibrium all markets clear.

We turn now to the formal maximization problem starting with the maximization of second period utility. Denoting by $R_{i}^{*}(i=1,2)$ the solution to the producers' profit maximization problem in period $i$ as implied by the solutions to $(A-3)-(A-4)$, we can write the maximization problem in period 2 as

$$
\begin{array}{ll}
\max u\left(C_{2}, L_{2}\right) \\
\text { s.t. } \quad C_{2}=(1+r) A_{1}+\left(\frac{W}{P}\right)_{2} L_{2}+R_{2}^{*}
\end{array}
$$

The solution to this problem yields $C_{2}^{*}$ and $L_{2}^{*}$ as the optimal values of consumption and labor supply in period 2. These optimal values are conditional, of course, on the historically given value of $A_{1}$. Thus, we can define a function $u^{*}\left(A_{1}\right)$ which denotes the expected value of second period's optimal utility. Thus, $u^{*}\left(A_{1}\right)=E\left[u\left(C_{2}^{*}, L_{2}^{*}\right)\right]$. The maximization problem for period 1 can then be presented as: 
$(A-6)$

$$
\begin{array}{ll} 
& \max u\left(C_{1}, L_{1}\right)+\tilde{\rho} u^{*}\left(A_{1}\right) \\
\text { s.t. } \quad C_{1}=Q+\left(\frac{W}{P}\right)_{1} L_{1}+R_{1}^{*}-A_{1}
\end{array}
$$

where $Q$ denotes the given initial endowment. The solution to $(A-6)$ yields the optimal values $\tilde{C}_{1}, \tilde{L}_{1}$ and $\tilde{A}_{1}$. For subsequent use we note that the optimal value of $A_{1}$ is chosen so as to satisfy the first order condition requiring that

$(A-7)$

$$
\tilde{\rho} \partial u^{*}\left(A_{1}\right) / \partial A_{1}=\partial u\left(C_{1}, L_{1}\right) / \partial C_{1} \quad .
$$

The value of utility in the general equilibrium is denoted by $U\left(\tilde{L}_{1}\right)$ where it is understood that this level of utility is obtained when $C_{1}, L_{1}$ and $A_{1}$ are set at their unconstrained optimal values $\tilde{C}_{1}, \tilde{L}_{1}$ and $\tilde{A}_{1}$. In practice, due to contracts, the level of employment might be constrained to $L_{1}$. The resulting level of utility would be $U\left(L_{1}\right)$ where it is understood that $C_{1}$ and $A_{1}$ are still chosen optimaliy subject to the constraint that the maximization of profits and the given nominal wage yield labor demand (and therefore employment) at the level $L_{1}$. The welfare cost of the constrained employment $\left(L_{1}\right)$ in terms of first period consumption is

$$
\frac{\Delta U}{\theta}=\frac{U\left(\tilde{L}_{1}\right)-U\left(L_{1}\right)}{\partial u\left(\tilde{C}_{1}, \tilde{L}_{1}\right) / \partial \tilde{C}_{1}} .
$$

where $\Delta U=U\left(\tilde{L}_{1}\right)-U\left(L_{1}\right)$ and where $\theta=\partial u\left(\tilde{C}_{1}, \tilde{L}_{1}\right) / \partial \tilde{C}_{1}$ denotes first period's marginal utility of consumption evaluated around the general equilibrium. 
In order to obtain an expression measuring the welfare loss we first compute the change in welfare associated with a marginal change in employment around an initial arbitrary level $L$. In what follows we compute the welfare cost for period 1 and we suppress the corresponding time subscript.Using equation $(A-6)$, the first order approximation of the change in welrare resulting from a marginal change in employment is

$(A-9) \quad U(L+\Delta L)-U(L)=[\partial u(C, L) / \partial C] \Delta C+[\partial u(C, L) / \partial L) \Delta L+\tilde{\rho}\left[\partial u^{*}(A) / \partial A\right] \Delta A$.

Using equation $(A-7)$ and expressing $(A-9)$ in terms of first period consumption yields

$$
\frac{U(L+\Delta L)-U(L)}{\partial U(C, L) / \partial C}=\Delta C-\left(\frac{W}{P}\right)^{S} \Delta L+\Delta A
$$

where $(W / P)^{S}=-\partial u(C, L) / \partial L$ denotes the real wage as measured along the supply of labor. From the definition of profits in (A-2) and the budget constraint in $(A-6)$ we note that

$$
C+A-Q=Y(L, V)-\frac{P}{P} V
$$

and, therefore,

$$
(A-11)
$$

$$
\Delta C+\Delta A=\frac{\partial Y}{\partial L} \Delta L+\frac{\partial Y}{\partial V} \Delta V-\frac{P V}{P} \Delta V
$$

Since produces always maximize profits, we may substitute the first order conditions $(A-3)-(A-4)$ into $(A-11)$ to obtain 
$\left(A 10^{\prime}\right) \quad \Delta C+\Delta A=\left(\frac{W}{P}\right)^{d} \Delta L$

where $(W / P)^{d}$ denotes the real wage as measured along the demand for labor. Substituting $\left(A-10^{\prime}\right)$ into $(A-10)$ yields

$(A-12) \quad \frac{[U(L+\Delta L)-U(L)] / \Delta L}{\partial u(C, L) / \partial C}=\left(\frac{W}{P}\right)^{d}-\left(\frac{W}{P}\right)^{s}$.

Finally we note that as $\Delta \mathrm{L} \rightarrow 0 \quad(\mathrm{~A}-12)$ becomes

$\left(A-12^{\prime}\right) \quad \frac{d U(L) / d L}{\partial u(C, L) / \partial C}=\left(\frac{W}{P}\right)^{d}-\left(\frac{W}{P}\right)^{s}$.

In computing the welfare loss we note that

$$
U\left(\tilde{L}_{1}\right)-U\left(L_{1}\right)=\int_{L_{1}}^{\tilde{L}_{1}} \frac{d U}{d L} d L
$$

Substituting this expression together with (A-12') into (A-8) yields

$$
\frac{\Delta U}{\theta}=\frac{1}{\partial u\left(\bar{C}_{1}, \tilde{L}_{1}\right) / \partial \bar{C}_{1}} \int_{L_{1}}^{\tilde{L}_{1}} \frac{\partial u(C, L)}{\partial C}\left[\left(\frac{W}{P}\right)^{d}-\left(\frac{W}{P}\right)^{s}\right] d L .
$$

Finally, assuming a constant marginal utility of consumption (i.e. assuming risk neutrality), $(A-12)$ can be written as

$\left(A-13^{\prime}\right)$

$$
\frac{\Delta U}{\theta}=\tilde{\int}_{L_{1}}^{\tilde{L}_{1}}\left[\left(\frac{W}{P}\right)^{d}-\left(\frac{W}{P}\right)^{s}\right] d L
$$


In order to obtain a more useful expression for the welfare loss we first express $\left(\frac{W}{P}\right)^{d}$ and $\left(\frac{W}{P}\right)^{S}$ in terms of the elasticities of supply and demand for labor. Using the definitions of elasticities the values of $\left(\frac{W}{P}\right)$ and $\left(\frac{W}{\mathrm{P}}\right)^{\mathrm{S}}$ around the general equilibrium are:

$$
\begin{aligned}
& \left(\frac{W}{P}\right)^{d}=\left(\frac{\tilde{W}}{P}\right)\left(1-\frac{\Delta L}{\bar{L} \eta}\right) \\
& \left(\frac{W}{P}\right)^{s}=\left(\frac{\tilde{W}}{P}\right)\left(1+\frac{\Delta L}{\tilde{L} E}\right)
\end{aligned}
$$

where $\Delta \mathrm{L}=\mathrm{L}-\tilde{\mathrm{L}}$, and where $\varepsilon$ and $\mathrm{n}$ denote the elasticities of the supply and the demand for labor. Substituting into $\left(A-13^{\prime}\right)$ yields

$$
\frac{\Delta U}{\theta}=\int_{L_{1}}^{\tilde{L}_{1}}\left(\tilde{\frac{W}{P}}\right) \frac{1}{\tilde{L}}\left(\frac{1}{E}+\frac{1}{n}\right)(\tilde{L}-L) d L
$$

Integrating the expression in $(A-14)$ yields

$(A-15)$

$$
\frac{\Delta U}{\theta}=\left(\frac{\tilde{W}}{P}\right) \frac{1}{\tilde{L}}\left(\frac{1}{\varepsilon}+\frac{1}{\eta}\right) \frac{(\tilde{L}-L)^{2}}{2} .
$$

The loss function $H$ is the expected value of $(A-15)$. Denoting by $Y_{0}$ and $L_{0}$ the equilibrium levels of output and employment obtained in the absence of stochastic shocks, we note that

$$
\Delta L=L-\tilde{L}=L_{0}\left(\frac{\left(L-L_{0}\right)-\left(\tilde{L}-L_{0}\right)}{L_{0}}\right)=L_{0}(l-\tilde{l})
$$

and 


$$
\tilde{L}_{0}=(1-\tilde{l}) \text {. }
$$

We also note that from the first order condition

$$
\left(\frac{\tilde{W}}{P}\right) \tilde{L}=B \tilde{Y}=B Y_{0}(1+\tilde{y})
$$

Substituting these expressions into (A-15), ignoring terms higher than second order terms of Taylor expansion, and computing the expected value $y i \in l d s$

$$
(A-16) \quad E\left[\frac{\Delta U}{\theta}\right]=E\left[\left(\frac{W}{P}\right)_{0} L_{0}\left(\frac{1}{\varepsilon}+\frac{1}{n}\right) \frac{(\tilde{l}-\ell)^{2}}{2}\right] .
$$

Finally, substituting equation (11) of the text for $(\tilde{l}-l)$ yields the loss function

$$
(A-17) \quad H=E\left\{\frac{1}{2} \eta \frac{\varepsilon+\eta}{\varepsilon}\left(\frac{1}{\varepsilon}+\frac{1}{\eta}\right)[-(w-p)+(w-p)]^{2}\right\}
$$

where $H$ is the approximation to $\frac{\Delta U}{\theta} /\left(\frac{W}{P}\right)_{0} L_{0}$. The expression in $(A-17)$ is the expected value of equation (13) in the text. 


\section{FOOTNOTES}

${ }^{1}$ This assumption is relaxed in Aizenman and Frenkel (1985) where it is assumed (in the context of a model without energy) that the value of the stochastic shock is not known at each point in time. In that case, behavior is governed by the conditional expectations of the shocks based on the available information.

2 The question concerning the efficiency of the assumed wage contract is addressed in section II.2, footnote 6 .

3 This expression corresponsd to equation $(A-17)$ in the Appendix. In order to obtain the welfare loss in units of output we need to multiply equation (13) by the equllibrium (non-stochastic) wage bill (W/P) $\mathrm{O}_{0}$. For a useful discussion of the measurement of the welfare cost see Harberger (1971).

${ }^{4}$ It is assumed that the initial contractual nominal wage is set at $W_{0}--$ the level that would have prevailed in equilibrium in the absence of shocks. Any other initial wage would not minimize the expected value of the welfare loss. In making this statement we use the approximation

$\log E_{t-1}\left(e^{u_{t}}\right)=E_{t-1}\left(u_{t}\right)$. This approxination is valid for small values of the variance and the realization of the stochastic shock $u$.

${ }^{5}$ For an analysis of optimal indexation rules see Fischer (1977a, 1977b).

${ }^{6}$ Tne assumption that employment is determined by the demand for labor was challenged by Cukierman (1980) who examined alternative specifications. As is evident with optimal policies, these issues turn inconsequential since, at the optimum, there is an equality between the demand and the supply of labor. Likewise, at the optimum the conceptual difficulties raised by Barro (1977) concerning the existence of suboptimal contracts, are also inconsequential since with optimal policies these contracts are in fact optimal. For a further discussion and rationalization of such contracts see Hall and Lazear (1984), and Fischer (1977b).

7 The specification in (17) constrained the coefficient of $p$ to be unity. More formally let the coefficient of $p$ in (17) be $b_{p}$; in that case the real wage is $w-p=\left(b_{p}-1\right)+b_{y} y$, and the level of output (using $6^{\prime}$ ) is $y=\left[-\left(b_{p}-1\right) p+\sigma u\right] /\left(1+B \sigma b_{y}\right)$. Substituting this expression into the real-wage equation and using equation (13) reveals that in order to equate the realized real wage with the equilibrium real wage, the coefficient of $p$ must be unity and the coefficient of $y$ must be $1 /(1+\varepsilon)$. It is also relevant to note that 
equation (17') corresponds to equation (15) in Karni (1983, p. 286). The precise analogy may not be apparent due to a typo-graphical error in Karni's equation (15). Using Karni's notations his coefficient of indexation to real output is $n /(w+n+\delta w n)$.

${ }^{8}$ For analyses of alternative proposals see Fischer (1977a) Eden (1979) Marston and Turnovsky (1983) and Marston (1984). For an analysis of alternative compensation systems and for a related discussion of employment versus real wage stabilization, see Weitzman (1983).

${ }^{9}$ It is relevant to note that with a Cobb-Douglas production function indexing nominal wages to nominal income is equivalent to indexing real wages to the real value of value added in terms of units of final output. To verify, define the real value added by $Y-\left(P_{V} / P\right) V$ and the percentage change thereof is: $\frac{y}{1-\lambda}-\frac{\lambda}{1-\lambda}(q+v)$. From the first-order conditions $\lambda Y / V=P_{v} / P$ and, therefore, $y=q+v$. It follows therefore that $\frac{y}{1-\lambda}-\frac{\lambda}{1-\lambda} y=y$. Marston and Turnovsky (1983) argue that the rule according to which nominal wages are indexed to the valueadded price index produces equivalent results to the rule by which real wages are indexed to real GNP. Our analysis shows that this equivalence holds only as long as there are no productivity shocks. Further, if the two rules are equivalent then they will be optimal only if, in addition, $\varepsilon=0$.

${ }^{10}$ The implicit assumption underlying this formulation is that all variables are stationary, i.e., that there are no trends, and that $E_{t} \log s_{t+1}$ is not influenced by the observed price. Therefore, in the absence of shocks, $i=\bar{i}$. Our assumption about the absence of trend allows us to focus on the properties of the stationary equilibrium for which the current values of the stochastic shocks do not affect the expectations about future values of the variables. In general, the stochastic shocks need not be identically and independently distributed with zero mean and a fixed variance. Allowing for a more general specification requires a modification of the definition of the bench-mark equilibrium that is obtained in the absence of shocks. With a more general specification of the stochastic shocks we let lower-case letters denote an innovation of a given variable. Thus, $x_{t}=\log x_{t}-E_{t-1} \log x_{t}$ instead of the specification which is adopted in the text according to which $x_{t}=\log x_{t}$ $\log x_{0}$. Obviously, in the special case discussed in the text, the assumed properties of the stochastic shocks imply that $E_{t-1} \log x_{t}=\log x_{0}$. With this interpretation of $x_{t}$ (as the innovation of $\log x_{t}$ ), the analysis can allow for trends in the various series and the various stocks may include permanent 
and transitory components. It is also relevant to note that the specification of equation (36) also embodies the assumption that the equilibrium is unique. The choice of the unique equilibrium is consistent with the criterion suggested by McCallum (1983). On the issue of uniqueness see Calvo (1970) and Turnovsky (1983).

${ }^{11}$ Relevant early references are Gordon (1975) and Phelps (1978). The focus on the question of accommodation in the presence of supply shocks is contained in Blinder (1981), Gordon (1984), and Fischer (1985), and various structural issues concerning adjustment to external shocks in an international setting are found in Bruno (1984), Bruno and Sachs (1982), Findlay and Rodriguez (1977), and Marion and Svensson (1982).

${ }^{12}$ phelps (1978) emphasizes the implications of an income elasticity differing from unity.

13 In the more general specification of the stochastic shocks (which was described in footnote $(10)$ ), the term $(\rho+x)$ in equation (37) would be replaced by the innovation in $i_{t}+\log P_{t}$ which can also be expressed as $i_{t}^{\prime}+E_{t} \log S_{t+1}+\log P_{t}^{\prime}$. Thus, the innovation of this term is $\left(i_{t}^{\prime}-E_{t-1} i_{t}^{\prime}\right)+E_{t} s_{t+1}+p_{t}^{\prime}$ where $E_{t} s_{t+1}=E_{t} \log s_{t+1}-E_{t-1} 10 z S_{t+1}$ and where $P_{t}^{\prime}=\log P_{t}^{\prime}-E_{t-1} \log P_{t}^{\prime}$. In order to obtain this expression for the innovation we first substitute equation (34) into the demand for money (equation (29)), and replace $\bar{i}$, (in equation (29')) with $E_{t-1} i_{t}^{\prime}$. Subtracting the resulting two equations from each other yields the more general expression corresponding to equation (37).

14 For an analysis of nominal-income targeting see Meade (1978), Poole (1980), Tobin (1980, 1983), Hal1 (1983), Bean (1983) and Taylor (1985). For discussions of a close variant of nominal-income targeting see McCallum (1984) and Mishkin (1984), and for other rules see Phelps and Taylor (1977). 


\section{REFERENCES}

Aizenman, Joshua and Frenkel, Jacob A. "Optimal Wage Indexation, Foreign Exchange Intervention and Monetary Policy." American Economic Review 75, No. 3 (June 1985), forthcoming.

Azariadis, Costas. "Escalator Clauses and the Allocation of Cyclical Risks." Journal of Economic Theory 18, Wo. 1 (June 1978): 119-55.

Barro, Robert $J$. "Long-term Contracting, Sticky Prices, and Moretary Policy." Journal of Monetary Economics 3. No. 3 (July 1977): 305-15. Bean, Charles R. "Targeting Nominal Income: An Appraisal." Economic Journal 93. No. 4 (December 1983): 806-19. Blinder, flan S. "Monetary Accommodation of Supply Shocks Under Rational Expectations." Journal of Money, Credit and Banking 13, No. 4 (November 1981): 425-38.

Blinder Alan S. and Mankiw, Gregory N. "Aggregation and Stabilization Policy in a Multi-Contract Economy." Journal of Monetary Economics 13, No. 1 (January 1984): 67-85.

Bruno, Michael. "Raw Materials, Profits, and the Productivity Slowdown." Quarterly Journal of Economies 99, No. 1 (February 1984): 1-30. Bruno, Michael and Sachs, Jeffrey. "Input Price Shocks and the Slowdown in Economic Growth: The Case of U.K. Manufacturing." Review of Economic Studies 5 (Special Issue, 1982): 679-705.

Calvo, Guillermo A. "On Models of Money and Perfect Foresight." International Economic Review 20, No. 1 (February 1979): 83-102.

Cukierman, Alex. "The Effects of Wage Indexation on Macroeconomic Fluctuations: A Generalization." Journal of Monetary Economics 6, No. 2 (April 1980): 147-70.

Eden, Benjamin. "The Nominal System: Linkage to the Quantity of Money or to Nominal Income." Revue Economique 30, No. 1 (January 1979): 121-43. 
Findlay, Ronald and Rodriguez, Carlos A. "Intermediate Imports and Macroeconomic Policy Under Flexible Exchange Rates." Canadian Journal of Economics 10 (May 1977): 208-17.

Fischer, Stanley (1977a). "Wage Indexation and Macroeconomic Stability." in Karl Brunner and Allan Meltzer (eds.) Stabilization of Domestic and International Economy, Carnegie-Rochester Conference Series on Public Policy, Vol. 5, a supplementary series to the Journal of Monetary Economics (1977): 107-47. (1977b). "Long Term Contracting, Sticky Prices and Monetary Policy: A Comment." Journal of Monetary Economics 3, No. 3 (July 1977): $317-23$

(1977c). "Long-term Contracts, Rational Expectations, and the Optimal Money Supply Rule." Journal of Political Economy 85, No. 1 (February 1977): 191-205.

- "Supply Shocks, Wage Stickiness, and Accommodation." Journal of Money, Credit and Banking, 17, No. 1 (February 1985): 1-15. Gordon, Robert J. "Alternative Responses of Policy to External Supply Shocks." Brookings Papers on Economic Activity 1 (1975): 183-206. - "Supply Shocks and Monetary Policy Revisited." America Economic Review 74, No. 2 (May 1984): 38-43.

Gray, Jo Anna. "Wage Indexation: A Macroeconcmic Approach." Journal of Monetary Economics 2, No. 2 (April 1975): 221-35.

Hall, Robert E. "Macroeconomic Policy Under Structural Cnange." in Industrial Change and Public Policy, Federal Reserve Bank of Kansas City, 1983: 85-111.

- Monetary Strategy with an Elastic Price Standard." in Price Stability and Public Policy, Federal Reserve Bank of Kansas City, 1984: $137-59$. 
and Lazear, Edward P. "The Excess Sensitivity of Quits and Layoffs to Demand." Journal of Labor Economics 2, no. 2 (April 1984): $233-57$.

Harberger, Arnold C. "Three Basic Postulates for Applied welfare Economics: An Interpretive Essay." Journal of Economic Literature 9, No. 3 (September 1971): 785-97.

Karni, Edi. "On Optimal Wage Indexation." Journal of Political Economy 91, No. 2 (April 1983): 282-92.

Marion, Nancy P. and Svensson, Lars E. O. "Adjustment to Expected and Unexpected Oil Price Increases." NBER Working Paper Series, No. 997. October 1982.

Marston Richard $C$. "Real Wages and the Terms of Trade: Alternative Indexation Rules for an Open Economy." Journal of Money Credit and Banking 16, No. 3 (August 1984): 285-301.

Marston, Richard C. and Turnovsky, Stephen J. "Imported Material Prices, Wage Policy and Macroeconomic Stabilization." NBER Working Paper Series, No. 1254, December 1983.

McCallum, Bennett $T$. "On Non-uniqueness in Rational Expectations Models: An Attempt at Perspective." Journal of Monetary Economics 11, No. 2 (March 1983): 139-68. - "Monetarist Rules in the Light of Recent Experiences." American Economic Review, 74 No. 2 (May 1984): 388-9l.

Meade, James E. "The Meaning of Internal Balance." Economic Journal 88 , No. 3 (September 1978): 423-35.

Mishkin, Frederic S. "The Causes of Inflation" in Price stability and Public Policy, Federal Reserve Bank of Kansas City, 1984: 1-24.

Phelps, Edmund S. "Commodity-Supply Shock and Full-Employment Monetary Policy." Journal of Money, Credit and Banking 10, No. 2 (May 1978): $206-221$. 
Phelps, Edmund S. and Taylor, John B. "Stabilizing Powers of Monetary Policy under Rational Expectations." Journal of Political Economy 85 , No. 1 (Eebruary 1977): 163-90.

Poole, William. "Comments on Paper by Tobin." Brookings Papers on Economic Activity $1(1930):$ 79-85.

Rasche, Robert H. and Tatom, John A. "Energy Price Snocks, Aggregate Supply and Monetary Policy: The Theory and the International Evidence." In Karl Brunner and Allan Meltzer (eds.) Supply Shocks, Incentives and National Wealth, Carnegie-Rochester Conference Series on Public Policy, Vol. 14. Amsterdam: North-Holland Pubiishing Co., 1981, pp. 9-93.

Taylor, John B. "Aggregate Dynamics and Staggered Contracts." Journal of Political Economy 88, No. 1 (February 1980): 1-23.

- "What Would Nominal GNP Targeting Do To the Business Cycle?" Carnegie-Pochester Conference Series on Public Policy, Vol. 22, Spring 1985, forthcoming.

Tobin, James. "Stabilization Policy Ten Years After." Brookings Papers on Economic Activity $1(1980):$ 19-71. - "Commentary" in Industrial Change and Public Policy, Federal Reserve Bank of Kansas City, 1983: 113-22.

Turnovsky, Stephen J. "Exchange Market Intervention Policies in a Small Open Economy." in Bhandari, J. and Putman B. (eds.) Economic Interdependence and Flexible Exchange Rates, Cambridge, MA: MIT Press, 1983, pp. 286311.

Weitzman Martin L. "Some Macroeconomic Implications of Alternative Compensation Systems." Economic Journal 93, No. 4 (December 1983): 763-83. 